\title{
O FÓRUM DE APRESENTAÇÃO NO CURSO DE FORMAÇÃo DE TUTORES CEAD/UFU: UM PANORAMA DO PERFIL DOS CANDIDATOS E SUA INTERATIVIDADE A PARTIR DO SNAPP
}

\author{
(THE PRESENTATION FORUM IN THE TRAINING OF TUTORS - CEAD / UFU: AN OVERVIEW OF \\ THE PROFILE OF CANDIDATES AND THEIR INTERACTION VIA “SNAPP”)
}

Olíria Mendes Gimenes

Universidade de São Paulo, Brasil

\section{RESUMO}

Este trabalho tem por objetivo traçar o perfil dos candidatos a tutores dos cursos a distância da Universidade Federal de Uberlândia (UFU) a partir das informações contidas nas postagens do fórum de apresentação, bem como aquelas registradas no questionário de avaliação do curso. Trata-se de uma pesquisa empírica, de abordagem qualitativa em que os dados foram avaliados a partir dos registros realizados pelos candidatos no Ambiente Virtual de Aprendizagem (AVA), do curso de Formação de Tutor para atuar na Educação a Distância, oferecido pelo CEaD/UFU em 2012. Relacionamos esses dados com as informações postadas no fórum de apresentação e a postura adotada pelo candidato nas interações exigidas nas atividades do fórum. Para analisarmos a interatividade no fórum utilizamos o software SNAPP. Percebemos que o conhecimento prévio se faz necessário no processo seletivo e formativo daqueles que irão atuar na EaD.

Palavras-chave: fórum, formação de tutores, educação a distância.

\begin{abstract}
This study aims to trace the profile of candidates during their tutorials in distance learning courses at the Federal University at Uberlândia, Brazil. The profile is based on the information contained in the online forum posts. It covers aspects from the questionnaire that are related to the course evaluation. It has an empirical and qualitative approach, i.e. where the data are evaluated using the candidates' entries in the Virtual Learning Environment of the Teacher Training Course, which was offered by CEad/UFU in 2012. Data were gathered from the forum and from the candidates' online behaviour, e.g. when interactions are required for completing forum activities. In order to analyze the forum interactions, we used software called SNAPP. We concluded that prior knowledge was needed in the selection and training process of those who work with DE.
\end{abstract}

Keywords: Forum, teacher training, distance education. 
A partir da LDB no 9.394/1996 a educação a distância (EaD) foi reconhecida na legislação brasileira, principalmente após a regulamentação de seu art. 80 com a publicação do Decreto $\mathrm{n}^{0} 5.622 / 2005$. Desde então, iniciou-se o processo de expansão dessa modalidade de ensino e a ascensão das instituições de ensino superior (IES) no cenário brasileiro.

Com esse advento, a Universidade Federal de Uberlândia (UFU) vem construindo a sua história na EaD, se mantendo parceira do Sistema da Universidade Aberta do Brasil (UAB), oferecendo cursos a distância de graduação, especialização, aperfeiçoamento e extensão.

A demanda instaurada pela oferta desses cursos fez com que a UFU criasse um órgão responsável pela gestão da $\mathrm{EaD}$ na instituição. Assim, nasceu o Centro de Educação a Distância (CEaD). Dentre suas atribuições está a formação de professores e de tutores para atuarem na EaD da UFU.

O CEaD é o responsável pelo processo seletivo dos tutores que irão atuar nos cursos a distância da UFU, principalmente pela $2^{\mathrm{a}}$ etapa, que diz respeito à formação dos candidatos. Diante da crescente demanda por formação de tutores por consequência da expansão da EaD na instituição, muito nos preocupa a qualidade do processo formativo dos atores envolvidos nos cursos a distância oferecidos pela UFU.

O processo seletivo simplificado para contratação temporária de tutores para atuarem na EaD/UFU é composto por duas etapas: a primeira, uma análise do currículo do candidato com apresentação comprobatória do que foi apontada na inscrição online; a segunda, o processo de formação oferecido pelo CEaD.

Diante disso, o grande número de candidatos inscritos nesses processos seletivos, bem como a extensa lista de espera de tutores a serem chamados, nos motiva a questionar sobre quem são esses candidatos interessados em exercer a tutoria na $\mathrm{EaD} / \mathrm{UFU}$. E como desdobramento dessa questão e atuando na realidade do curso de formação, se as informações registradas pelo candidato no AVA, bem como a sua desenvoltura durante o curso de formação, caracterizam indícios de potencialidades para o exercício da tutoria.

Estamos cientes de que muitos outros fatores elementares estão subjacentes a essa questão, contudo, nos limitaremos a elementos preliminares, sendo necessários outros indicadores a serem ampliados, bem como aprofundamentos na matéria, que poderão vir a ser fruto de outros estudos. 
Nesse sentido, o objetivo deste trabalho é traçar o perfil dos candidatos a tutores a partir das informações contidas nas postagens do fórum de apresentação, bem como aquelas registradas no questionário de avaliação do curso.

O contexto deste estudo é o Curso de Formação de Tutor para atuar na Educação a Distância (FTEAD) oferecido pelo CEaD/UFU no ano de 2012. Os sujeitos que dele fazem parte são os cursistas de uma das salas virtuais que compuseram a Turma 6 . Essa sala foi composta por 19 candidatos a tutores de um curso de especialização lato sensu oferecido pela Faculdade de Educação da UFU.

Os dados foram construídos a partir dos registros realizados pelos candidatos no Ambiente Virtual de Aprendizagem (AVA) - Moodle, sendo que nos apropriamos das informações contidas tanto no fórum de apresentação quanto no questionário de avaliação do curso, que foram compilados de modo que pudessem ser analisadas.

A nossa análise será feita a partir de uma abordagem sócio-histórico-cultural, sob a luz dos pressupostos teóricos de Vigotski em relação a pensamento e linguagem, juntamente aos de Bakhtin, no que se refere a língua/linguagem. Os dados obtidos serão relacionados com as informações postadas no fórum de apresentação e a postura adotada pelo candidato nas interações exigidas na atividade do fórum.

Por conseguinte, este estudo está estruturado por subitens de modo a possibilitar a compreensão de sua intencionalidade, sendo que o primeiro expõe a formatação do Curso de Formação de Tutores CEaD/UFU, bem como a sua proposta de ensino. No segundo, apresentamos o perfil dos candidatos a tutores, sujeitos deste estudo, indicando dados referentes a aspectos relacionados à faixa etária, formação acadêmica, experiências e conhecimentos sobre a EaD. Em seguida, discutimos o papel do fórum de apresentação no âmbito do curso de formação evidenciando as potencialidades dessa ferramenta dentro de um curso a distância. Ao final, utilizamos um programa computacional para representar a interatividade dos candidatos a tutores no fórum, demonstrando assim, o nível de interação proporcionado pela atividade.

\section{O CURSO DE FORMAÇÃO DE TUTORES CEAD/UFU}

$\mathrm{O} \mathrm{CEaD} / \mathrm{UFU}$ atua em parceria com as unidades acadêmicas apoiando administrativamente no que concerne a realização dos cursos a distância. Com a ampliação da EaD na UFU, tem crescido a oferta de cursos nessa modalidade, seja a nível de graduação, especialização latu sensu, aperfeiçoamento ou extensão. Em 
consequência, há a necessidade de formação de tutores e de professores autores e/ ou formadores para atuarem nesses cursos.

De forma a atender a demanda de formação dos profissionais que pretendem atuar na $\mathrm{EaD}$, o $\mathrm{CEaD}$ passou a ser o responsável pelo processo formativo inicial atendendo, assim, as exigências da obrigatoriedade da legislação vigente, que prevê o desempenho satisfatório nos cursos de formação na UFU para atuarem como professores e tutores dos cursos oferecidos a distância. Vale ressaltar que está prevista a formação continuada dos tutores, oferecida pela unidade acadêmica em que irão atuar.

A obrigatoriedade é uma prerrogativa da UAB. O tutor para atuar na modalidade a distância necessita da certificação do Curso de Formação de Tutores para a $\mathrm{EaD}$ oferecido por algumas IES. No caso da UFU, o tutor que deseja atuar nessa modalidade necessita da certificação expedida pelo CEaD/UFU.

Pautado nessa premissa, o curso do CEaD está estruturado a partir dos seguintes objetivos: 1) formar tutores para compreensão das dimensões tecnológicas existentes no ambiente da EaD contemporânea; 2) possibilitar ao tutor conhecer as propostas de ensino/ aprendizagem, avaliação e mediação pedagógica que darão subsídios para o desenvolvimento de seus trabalhos na modalidade de EaD para os cursos oferecidos pela UFU; 3) capacitar tutores para o desenvolvimento de atividades de orientação a tutoria nos cursos realizados na modalidade de EaD oferecidos pela UFU.

Nesse sentido, o CEaD oferece o Curso de Formação de Tutores para atuar em $\mathrm{EaD}$ desde maio de 2010, com sete edições já ofertadas. O curso faz parte do processo de seleção de tutores e é requisito para classificação e atuação nos cursos oferecidos na modalidade a distância.

O curso possui caráter eliminatório e classificatório, sendo a aprovação no curso condicionada à participação em, pelo menos, $75 \%$ das atividades programadas, bem como o aproveitamento de, no mínimo, 60\%. Dez por cento do total da nota do curso são destinados à pontuação dos seguintes itens: assiduidade no ambiente virtual, uso adequado da língua/gramática, linguagem (netiqueta EaD), capacidade de organização e de liderança, interação com a turma e com o tutor. Caso o candidato não obtenha a aprovação, será considerado automaticamente eliminado e não será classificado para fazer parte do banco de tutores do curso da UFU para o qual se inscreveu. 
O curso é realizado no AVA Moodle e conta com dois encontros presenciais, um no início e outro no final. Eles acontecem no próprio espaço da instituição. Desde a quinta edição, realizada em 2012, houve uma reformulação no curso - no que se refere à carga horária (presencial e à distância), bem como no conteúdo didáticopedagógico. Antes, era de 60 horas, e atualmente é de 80 horas.

O primeiro encontro é realizado com o coletivo de candidatos visando apresentar a equipe $\mathrm{CEaD}$ e explicar a dinâmica do curso que, de maneira geral, apresenta os mitos e dúvidas sobre a EaD. Destaca algumas questões sobre tutoria relacionadas às suas funções e competências, o que se espera do aluno que estuda à distância, como deve ser a comunicação nessa modalidade, os pontos de sustentação da qualidade da EaD e o sistema de tutoria, apresentando o papel do tutor presencial e do tutor a distância.

O segundo encontro geralmente é realizado no laboratório de informática do $\mathrm{CEaD}$, quando o número de candidatos aprovados no curso de formação assim o permite, e tem como objetivo apresentar o AVA no perfil de tutor. Esse encontro focaliza questões pertinentes à atividade de tutoria, bem como a dinâmica existente nas diversas ferramentas presentes no ambiente. A fala presente nesse encontro se dirige à discussão sobre algumas questões envolvendo as tarefas, à abertura de fóruns, aos chats, às wikis, ao acesso ao AVA, à interação, à linguagem, à mediação pedagógica, à proximidade com o aluno e à avaliação. Ao final desse encontro, encerra-se oficialmente o curso e são entregues os certificados.

Atualmente, o curso possui uma carga horária de 80 horas, sendo oito horas presenciais (divididas em dois encontros presenciais de quatro horas cada) e 72 horas a distância, no ambiente Moodle. O curso é organizado em quatro módulos com turmas de até 25 cursistas. As horas no AVA são divididas em quatro módulos, conforme o conteúdo abaixo discriminado:

- Módulo I - Fundamentos da educação - fundamentos e desenvolvimento: Ambiente Virtual de Aprendizagem (AVA); Concepções de Educação a Distância (EaD); Histórico da EaD; Legislação; A Universidade Aberta do Brasil (UAB).

- Módulo II - Planejamento e gestão em educação a distância: A educação a distância na UFU; A importância do ato de planejar; Projeto de cursos na modalidade de educação a distância; Profissionais envolvidos na oferta de cursos na EaD; Planejamento de uma disciplina em cursos a distância. 
- Módulo III - Tutoria - teoria e práticas: Características do estudar e trabalhar a distância; Concepção de tutoria; Saberes necessários a tutoria como tarefa educativa; Atribuições e Experiências do tutor na UAB na UFU.

- Módulo IV - Atuação do professor autor e formador no curso e na tutoria: Concepções de trabalho docente na EaD; Características do trabalho do professor autor e formador na EaD; Características do trabalho do tutor (presencial e a distância); Formas de acompanhamento e avaliação de cursos na $\mathrm{EaD} / \mathrm{CEaD} / \mathrm{UFU}$.

A proposta do curso aborda diversas mídias como recurso didático, de forma a familiarizar o tutor quanto às possibilidades do universo da $\mathrm{EaD}$, promovendo vivências significativas capazes de provocar novas percepções em relação a elas. Todo esse movimento é sempre permeado por uma linguagem dialógica.

Em relação à avaliação, ela é processual e ocorre ao longo de todas as semanas do curso. São apresentadas avaliações por meio de atividades síncronas e assíncronas. Toda e qualquer atividade, ainda que não se atribua uma nota, é acompanhada pelos responsáveis.

Ao final do último módulo, o candidato cursista é convidado a participar do processo de avaliação do curso, respondendo dois questionários. Vale ressaltar que esse momento é importante, pois é quando o candidato pode expor, por meio do instrumento de avaliação, o seu parecer sobre os processos de ensino e aprendizagem, tutoria, ambiente virtual de aprendizagem, material didático, dentre vários outros aspectos que, conjuntamente, fazem com que o curso se realize.

Os questionários têm como finalidade possibilitar o levantamento de dados com vistas a subsidiar a avaliação, o acompanhamento e o aprimoramento do curso, zelando por um curso de qualidade construído em parceria com um(a) cursista que compartilha e requer essa qualidade. A partir de algumas dessas respostas é que iremos construir os dados deste trabalho.

\section{O PERFIL DOS CANDIDATOS A TUTORES}

Os candidatos que foram classificados na primeira etapa do processo de seleção de tutores são convocados a realizarem o curso de formação ofertado pelo $\mathrm{CEaD} /$ UFU. Assim, os candidatos são matriculados no curso e recebem um login para dar início a segunda etapa. 
Ao acessarem o AVA Moodle são instruídos a comporem o perfil e inserirem sua foto de maneira que os outros integrantes da sala virtual o reconheçam por ela. Nesse momento, duas enquetes são apresentadas a eles com a finalidade de acessarmos o seu conhecimento prévio sobre $\mathrm{EaD}$ e suas experiências na área.

Na primeira, que trata sobre as dificuldades com as ferramentas do computador e da Internet, 15 cursistas (83,3\%) indicaram que utilizam com facilidade as várias ferramentas do computador e da Internet, sendo que do total, dois $(11,1 \%)$ sinalizaram que utilizam com certa dificuldade as várias ferramentas do computador da Internet, e, apenas um $(5,6 \%)$ deles, se considerou um expert no assunto.

Na segunda, que trata de questões experienciais com a EaD, sete $(38,9 \%)$ do total de candidatos indicaram ter algum conhecimento e alguma experiência no que se refere à modalidade; quatro $(22,2 \%)$ indicaram que têm amplo conhecimento $\mathrm{e}$ experiência na $\mathrm{EaD}$; seis $(33,3 \%)$ cursistas indicaram que participam ativamente em diferentes instâncias da $\mathrm{EaD}$, considerando-se completamente envolvidos com essa modalidade de ensino; e, apenas um $(5,6 \%)$ registraram nunca ter participado de $\mathrm{EaD}$, mas já fizeram algumas leituras sobre o assunto.

A partir dessa enquete de conhecimento prévio sobre educação a distância, já temos um panorama inicial do perfil dos candidatos a tutores, sugerindo que na sala virtual em foco, composta, inicialmente, por 19 cursistas, quatro são do gênero masculino e o restante do gênero feminino, sendo que todos possuem conhecimentos e experiências que os permitem manusear minimamente o computador e a Internet. Desse número, uma cursista não respondeu as enquetes.

Com o propósito de conhecer quem são esses candidatos a tutor e traçar um perfil da sala, no que se refere aos aspectos de faixa etária, formação acadêmica, profissionalidade, nos apropriamos de algumas das informações registradas no questionário de avaliação do curso de formação de tutores $\mathrm{CEaD} / \mathrm{UFU}$, bem como as registradas nas postagens do fórum de apresentação do curso, para construirmos os dados que passamos a explorar.

Assim, no que se refere à faixa etária dos candidatos, conforme a Fig.1, podemos observar que a grande maioria se concentra na faixa etária de 31 a 40 anos, sendo 11 cursistas, correspondendo a $61,1 \%$ do total, e apenas dois $(11,1 \%)$ cursistas estão na faixa de mais de 50 anos. 


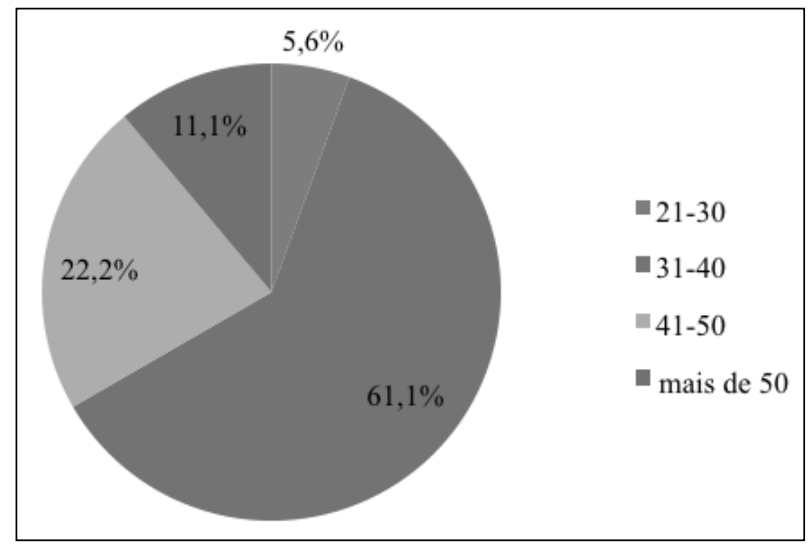

Figura 1. Faixa etária dos candidatos a tutores

Conforme as legislações vigentes e de acordo com as normas estabelecidas pelos centros de educação a distância das IES, para ser tutor no Sistema UAB, não existe uma exigência quanto à idade máxima, sendo necessário apenas ter a certificação do ensino superior, preferencialmente na área em que irá atuar. Vale lembrar que o processo seletivo para tutor fica a cargo de cada instituição, não existindo um modelo padrão a seguir.

Nesse caso, em específico, não foi exigida uma formação específica, tendo em vista tratar-se de um curso de especialização lato sensu, sendo requisitadas algumas exigências expressas no Edital, conforme consta o item 3.2 da Chamada Pública 02/2012 que versa sobre o processo seletivo simplificado para contratação de tutores a distância e presenciais temporários:

3.2 - Poderão candidatar-se a vagas para exercer as funções de tutores presenciais ou a distância os candidatos que atendam às condições mínimas exigidas quais sejam:

a) Graduação concluída em qualquer licenciatura ou em Comunicação Social;

b) Ter, conforme disposto na Lei no ${ }^{0} 11.273$ de 06/02/o6, na Resolução no 26 de 05/06/o9, experiência mínima de 1 (um) ano no magistério do ensino básico (Ensino Infantil, Fundamental ou Médio) ou Ensino Superior, OU ter formação pós-graduada, OU estar vinculado a programa de pós-graduação (FACED/CEaD-UAB/UFU, 2012, p.3).

Diante disso, do total de candidatos a tutor do curso de especialização lato sensu em análise foram apontadas as seguintes licenciaturas, seguidas da quantidade de 
cursista: Matemática (1), Geografia (4), Pedagogia (7), Educação Física (1), Letras (2), História (2) e Química (1).

A formação dos candidatos em nível de pós-graduação lato sensu está demarcada na área da educação, voltada para o ensino e para a gestão escolar, entretanto, cinco cursistas indicaram ser especialistas na área das tecnologias da informação e comunicação e na área de design instrucional virtual. No que tange a formação strictu sensu, do total de candidatos a tutores, 12 possuem mestrado, três doutorado e quatro estão com o doutorado em andamento.

Durante a segunda etapa do processo seletivo de tutores, $16(88,9 \%)$ candidatos estavam trabalhando e apenas dois $(11,1 \%)$ indicaram estar desempregados. Todos os que marcaram estar trabalhando, estão na área da educação, indicando a educação básica e o ensino superior, destacando que dois deles informaram já serem tutores de cursos a distância.

Uma das perguntas do questionário é sobre o conhecimento em relação à EaD antes de fazer o curso de formação de tutores. Do total de cursistas, 14 (77,8\%) deles já a conheciam por ter atuado academicamente e/ou profissionalmente na área; dois $(11,1 \%)$ já foram alunos de cursos a distância; e, dois $(11,1 \%)$ não conheciam ou tinham informações limitadas.

No que diz respeito à experiência profissional em cursos de $\mathrm{EaD}$, seis (33,3\%) responderam já ter atuado em cursos a distância como professor; cinco $(27,8 \%)$ já aturam em cursos a distância como tutor; e, sete $(38,9 \%)$ marcaram a opção outros, esclarecendo ter experiência de conteudista em cursos de graduação a distância, de coordenador de cursos EaD, e programador de AVA.

Uma questão específica sobre o Moodle consta no questionário, referindo-se ao conhecimento do candidato ao AVA. As respostas registradas pelos cursistas demonstraram que seis (33,3\%) do total, já conheciam o ambiente Moodle por tê-lo utilizado como professor e/ou tutor em cursos a distância que utilizava o Moodle; cinco $(27,8 \%)$ deles conheciam por já terem sido alunos de um curso a distância que utilizava o Moodle; porém, sete $(38,9 \%)$ do total de candidatos não conheciam o AVA Moodle.

Esse quantitativo está representado na Fig. 2 e se apresenta de certa maneira equilibrado, no entanto, devemos considerar o número de candidatos que não conheciam o Moodle antes da formação. Os sete cursistas, o equivalente a 38,9\%, ou seja, quase a metade dos candidatos, que afirmam não conhecerem a plataforma 
Moodle nos deixam em alerta, pois o curso em que irão atuar utiliza esse ambiente e requer desenvoltura para lidar com as ferramentas nele contidas, sendo que é por meio dela que os alunos dos cursos EaD irão desenvolver as atividades propostas e eles, e os futuros tutores irão mediar todo o processo de ensino, inclusive avaliar a participação dos alunos no AVA.

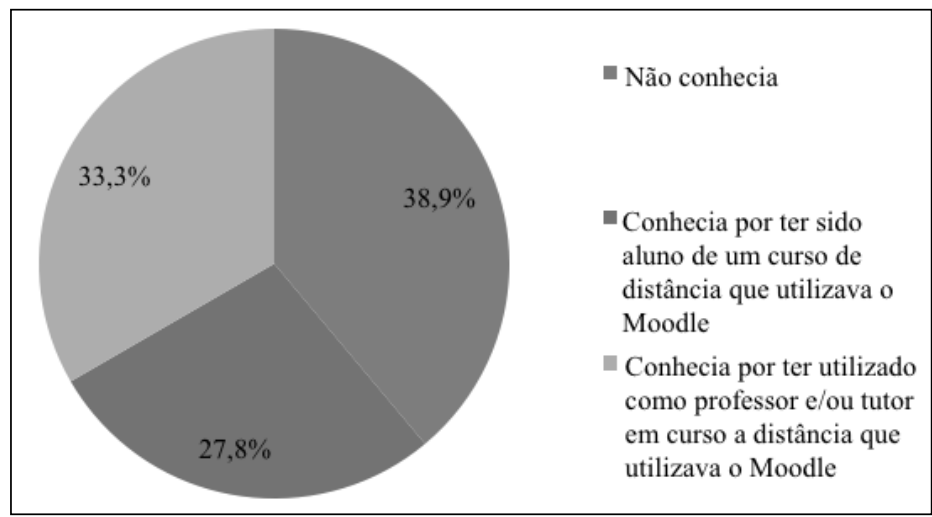

Figura 2. Conhecimento do AVA Moodle antes do Curso de Formação de Tutores

Em suma, podemos afirmar que o perfil dos candidatos a tutor para atuarem no curso de especialização lato sensu, Chamada Pública $\mathrm{n}^{0}$ 02/2012, são em sua maioria do sexo feminino, concentrado na faixa etária dos 31 a 40 anos de idade, todos com formação acadêmica em nível superior, em sua maioria com formação latu sensu e alguns strictu sensu. De modo geral, todos trabalham na área da educação, sendo que alguns atuam na educação básica concomitantemente ao ensino superior ou mesmo na tutoria em outras instituições. A grande maioria possui experiência na $\mathrm{EaD}$ por ter atuado profissionalmente na área, seja como docente, tutor, ou em outras atividades. Quase a metade do total de candidatos conheceu o AVA Moodle no curso de formação de tutores $\mathrm{CEaD} / \mathrm{UFU}$.

\section{O PAPEL DO FÓRUM DE APRESENTAÇÃo}

Dentre as diversas ferramentas assíncronas que o Moodle oferece, uma delas é o fórum. É uma atividade assíncrona de interação entre professores e alunos que permite a constituição de um grupo de aprendizagem capaz de criar um ambiente de discussão de ideias. 
Esse recurso permite àqueles que são mais tímidos expressarem suas ideias sem medo da exposição oral, além de permitir aos participantes da atividade inserirem suas opiniões sem pressão da cobrança da resposta imediata.

As exposições de diferentes opiniões permitem que alunos e professores, no contexto de um curso a distância, construam seus pensamentos a partir das opiniões postadas no fórum, tornando-o um intenso processo de construção e reconstrução de ideias.

Do ponto de vista técnico, existem quatro tipos de fórum, quais sejam: fórum geral, fórum de simples discussão, fórum de pergunta e resposta, e fórum em que cada usuário pode iniciar somente um novo tópico. Cada fórum é definido como:

- "Fórum geral: nesse tipo de fórum a abertura de tópico é ilimitada, podendo qualquer usuário abrir a quantidade de tópicos que achar necessária para a discussão do tema proposto.

- Fórum de simples discussão: nesse fórum existe um único tópico, estabelecido previamente pelo professor. Os participantes da atividade só poderão postar seus comentários no tópico aberto, não sendo possível abrir novos tópicos de discussão paralelos ao tema central.

- Fórum de pergunta e resposta: é postado no fórum um questionamento para que todos os participantes postem suas contribuições sobre o tema. Diferentemente dos outros tipos de fórum, a aluno só poderá ver a resposta já postada por um colega após ele postar sua contribuição.

- Fórum em que cada usuário pode iniciar somente um novo tópico: nesse fórum cada usuário pode abrir somente um novo tópico relacionado ao tema de discussão do fórum, diferente do fórum geral: a abertura de tópicos é ilimitada" (Arruda e Mourão, 2012, p. 29).

A ferramenta fórum está presente em todos os módulos do curso de formação de tutores, sendo que a nossa apresentação será o pertencente ao Módulo 1, por ter uma característica diferenciada dos demais, a apresentação pessoal do candidato.

O conteúdo do Módulo 1 - Educação a Distância: fundamentos e desenvolvimento - aborda assuntos sobre o AVA Moodle; as concepções de EaD; o histórico e a legislação da EaD; e, a Universidade Aberta do Brasil (UAB), e, tem como objetivo identificar e discutir a concepção de EaD; situar historicamente a construção do conhecimento e da prática de EaD; apresentar a legislação sobre a EaD no Brasil; e, explorar o AVA Moodle. 
O primeiro módulo do curso prevê seis atividades obrigatórias e atividades complementares. Das obrigatórias, três são avaliativas e perfazem um total de 20 pontos, sendo elas: fórum de apresentação, diário de bordo e resumo. As atividades complementares são indicações de leituras e vídeos, não entrando no cálculo somativo do processo avaliativo.

A atividade, fórum de apresentação, é um convite inicial para que os cursistas se apresentem aos outros colegas, integrantes da sala virtual, no intuito de fazer uma breve apresentação pessoal e estabelecer vínculos, além de manipular uma ferramenta assíncrona, de caráter interativo presente no AVA Moodle.

Por meio da manipulação dessa ferramenta assíncrona, presente em qualquer AVA que, geralmente faz parte dos cursos a distância, os cursistas iniciam uma comunicação mediada por computador com os outros participantes do curso, sempre tomando o cuidado com a escrita no ambiente, pois

na comunicação mediada por computador, em ambientes virtuais de aprendizagem atualmente disponíveis, o processo enunciativo depende quase que exclusivamente das trocas textuais, subtraídas das possibilidades de uso de linguagens não-verbais, gestos, expressões faciais, olhares, tom de voz, etc. Essas características da comunicação mediada por computador interferem na ação educativa de tal modo, que a organização do ensino pode vir a se estruturar preferencialmente em atividades de caráter interativo e colaborativo, nas quais os papéis desempenhados por professores e alunos sejam redimensionados na direção de privilegiar a negociação de significados em detrimento da transmissão de informações. O potencial transformador dos papéis sociais ocupados por alunos e professores na construção de significados depende, em larga medida, da forma como se desenvolvem as interações verbais nos ambientes virtuais de aprendizagem (Dotta; Giordan, 2008, p.128).

O fórum de apresentação do Módulo 1 possui a característica de apresentação informal do participante do curso, uma maneira dele se colocar diante do grupo em relação aos aspectos pessoais, profissionais, acadêmicos, mas nos outros módulos do curso de formação, a ferramenta fórum, se apresenta com outros atributos, a depender do conteúdo e dos objetivos propostos.

Entretanto, cabe ao tutor direcionar as interações nesse espaço virtual, não cabendo um desvirtuamento do assunto proposto na atividade, por isso:

[...] as interações entre tutor-aluno ocupam lugar central em atividades não-presenciais que objetivam a aprendizagem, e a prática dessas interações precisa considerar aspectos do discurso textual corrente em interações virtuais, de sua aplicação em atividades educacionais, das características da linguagem utilizada em comunicação mediada 
por computadores, dos aspectos sociais e tecnológicos que possam interferir nessa comunicação (Dotta e Giordan, 2007, p. 2).

O responsável pela abertura de todos os fóruns é o tutor e no caso em específico do curso de formação de tutores CEaD/UFU é ele quem abre o fórum e posta a sua apresentação pessoal em conformidade com as instruções contidas no escopo da atividade e os cursistas vão inserindo as suas a partir da postagem de seu tutor. Por ser um fórum, sugere-se que haja interações entre os cursistas, de maneira que os integrantes da sala virtual possam se conhecer melhor, pois esse é um dos objetivos da atividade. A proposta da atividade constante no AVA está assim descrita:

Prezados/as alunos/as,

Este é nosso primeiro fórum! Vamos aproveitá-lo para nos conhecermos um pouco mais? Participe deste Fórum fazendo uma breve apresentação sobre você! Antes de postar sua apresentação pessoal, gostaríamos de propor uma sequência para a postagem, iniciando com uma busca na web. Utilizando um mecanismo de busca de imagem (como o Google, por exemplo), tente encontrar uma imagem que retrate sua personalidade, sua visão de vida ou mesmo de educação. Remeta a essa imagem no seu texto.

Não se esqueça de inserir os itens a seguir:

- Postar a foto no seu perfil.

- Seu nome e a cidade onde você nasceu ou mora.

- Sua formação acadêmica.

- Informações profissionais.

- Informações pessoais: família, gostos, dentre outros.

- Informações sobre a imagem escolhida.

- Expectativas em relação ao curso.

Tente falar de maneira mais informal. Evite os termos acadêmicos, típicos do currículo Lattes. Poste sua apresentação a partir da postagem de seu tutor(a) clicando em responder. Leia as apresentações dos colegas e comente-as! Esta é uma ótima oportunidade para encontrar colegas com perfis similares ao seu. Aproveite!

O passo-a-passo para participação no fórum está no guia de estudos do primeiro módulo. Observe a importância da apresentação dos alunos que estudam a distância. Lembre-se de que, como não há presença física, a "presença virtual” é a única forma dos estudantes se conhecerem.

Bom trabalho a todos!

Valor da actividade: 5 pontos 
O autor do Módulo 1 assim como da atividade fórum de apresentação, cuidou para que a proposta fosse elaborada com uma linguagem mais próxima possível dos participantes do curso. Ele elaborou a atividade com palavras pertencentes a um contexto social comum, utilizando marcações de visualização e, ainda, signos linguísticos incomuns nas linguagens escrita e falada.

Isso nos permite resgatar a tese defendida por Bakhtin (2010) de que a língua é considerada um produto coletivo, sempre apresentado dentro de um contexto ideológico, inclusive, podendo dizer que a língua/linguagem constituída dentro dos grupos sociais (infraestrutura) possui características próprias que foram estabelecidas pelos seus integrantes, sendo estes pertencentes a uma dada realidade social (superestrutura) e, que, para se estabelecer diálogos nesses grupos, o enunciado deve ser condizente com o contexto desses grupos sociais.

Por meio das informações postadas no fórum pelos candidatos é possível perceber que a grande maioria considerou a atividade como um exercício interativo que possibilitava conhecer seu colega, além de receber comentários de seu post e vice-versa.

A maneira como o fórum de apresentação foi se desenvolvendo ao longo do módulo, a dinâmica das postagens e o rápido retorno dos comentários produzidos e endereçados aos cursistas, proporcionou uma maior abertura de informações pessoais, podendo dizer que ao inserir uma postagem o candidato tinha a certeza de que ela seria lida e comentada, crendo que aquele espaço seria sim, um espaço de início de novas amizades, e quem sabe de possíveis encontros presenciais, sendo que alguns residiam na mesma cidade sem se conhecerem.

Esse fenômeno ocorrido no ambiente do fórum é resultado de uma enunciação socialmente dirigida e determinada pelos participantes do diálogo, pois:

[...] a situação dá forma à enunciação, impondo-lhe esta ressonância, em vez daquela, por exemplo a exigência ou a solicitação, a afirmação de direitos ou a prece [...]. A situação e os participantes mais imediatos determinam a forma e o estilo ocasionais da enunciação (Bakhtin, 2010, p. 118).

Ao construírem as suas mensagens os participantes tiveram que buscar pelo pensamento, linguagem interior, o que queriam dizer de forma escrita, exigindo, assim, uma alta complexidade de suas funções psíquicas superiores, pois:

A linguagem interior é uma linguagem estenográfica reduzida e abreviada no máximo grau. A escrita é desenvolvida no grau máximo. [...] Trata-se de uma linguagem orientada 
no sentido de propiciar o máximo de inteligibilidade ao outro. [...] A passagem da linguagem interior abreviada ao máximo grau, da linguagem para si, para a linguagem escrita desenvolvida no grau máximo, linguagem para o outro, requer da criança operações sumamente complexas de construção arbitrária do tecido semântico (Vigotski, 2009, pp. 316-317).

A relação da imagem postada com o texto escrito da apresentação pessoal permite projetar a constituição do cursista, ao ponto de estabelecermos características sobre a sua rotina pessoal e de trabalho, as suas concepções de vida, de família e de educação. Alguns dos cursistas se identificaram com a imagem postada pelos colegas, demonstrando assim, possíveis afinidades dentro do curso de formação, conforme os diálogos constantes dos quadros 1, 2 e 3.

O pensamento dos cursistas contém significados que foram mediados por palavras e pela imagem, que são os signos, e que foram inseridos em um espaço público aos demais, o fórum, que é um instrumento do AVA. Diante disso, concordamos que:

[...] O pensamento não é só externamente mediado por signos como internamente mediado por significados. Acontece que a comunicação imediata entre consciências não é impossível só fisicamente mas também psicologicamente. Isto só pode ser atingido por via indireta, por via mediata. Essa via é uma mediação interna do pensamento, primeiro pelos significados e depois pelas palavras. Por isso o pensamento nunca é igual ao significado direto das palavras. O significado medeia o pensamento em sua caminhada rumo à expressão verbal, isto é, o caminho entre o pensamento e a palavra é um caminho indireto, internamente mediatizado (Vigotski, 2009, p. 479).

Percebemos nas mensagens dos cursistas que o conjunto, imagem e palavras, compondo o discurso, desencadearam processos que ultrapassaram o teor lexical, conforme argumentou Vigotski (2009). A comunicação mediata de pensamentos do autor da postagem inicial conseguiu atingir os outros participantes, estabelecendo assim, a construção de significados pelo colega mediante um olhar singular, mas ao mesmo tempo, este, se convergia muito próximo ao do autor inicial, conforme os diálogos 1 e 2 nos Quadros 1 e 2, respectivamente.

M.M.E. - quarta, 26 setembro 2012, 08:55

C., bom dia.

Achei linda sua imagem. A grande árvore com suas raízes que penetram o solo nos dando segurança, base, ação para sobrevivermos neste mundo, mas sem esquecer os degraus da evolução espiritual. Espero que possamos estabelecer um bom relacionamento, pois me identifiquei com sua fala.

Um abraço e bom curso.

M. 


\section{C.N.M. - quinta, 27 setembro 2012, 15:17}

Oi M., Boa tarde!

Que bom que você fez leitura, porque era exatamente o que eu queria dizer: Evoluir, sem esquecer o que nos dá sustentação! Certamente, estabeleceremos um bom relacionamento, pois eu também já havia me identificado com a sua fala.

Abração e Obrigada!

C.

Quadro 1 - Diálogo 1

K.R.O. - sexta, 28 setembro 2012, 08:02

Que imagem liiiiiinda! Amei!

Também gostei muito do que escreveu!

Adoooro dança. Sempre dancei. Porém, as muitas obrigações do dia a dia me privaram disso. Tenho tentado retornar, mas os horários têm sido incompatíveis, infelizmente.

Fiquei pensando ainda nas oposições presentes na mesma imagem e pensei que ela se assemelha a nós: claro, escuro, sol, lua, troncos espessos, troncos finos... Pensei em como é bonito apreciar todas essas nuances na vida, em nós mesmos, como tudo isso compõe a linda imagem da vida, a qual devemos observar minuciosamente, vendo um pequeno pássaro vermelho, estrelas reluzentes...

Parabéns pelo bom gosto!

Sucesso no curso!

Sucesso na vida!

K.

C.N.M. - sexta, 28 setembro 2012, 13:19

Oi K.!

Que bom que gostou da imagem!

Passo um bom tempo observando, na imagem e na vida real, essas nuances que você citou. Você é da terrinha da Dona Beija, lugar abençoado, gosto muito da cidade, tenho familiares por aí!

Quanto à dança, é como você disse: a correria do cotidiano também têm me impedido de continuar. Mas nós vamos achar uma brecha para prosseguir nessa atividade que tanto nos fascina!

Um grande abraço,

C. 
A.C.T. - sexta, 28 setembro 2012, 11:24

M., obrigado pelo carinho. Vamos manter contato sim, claro. Moro em Uberaba e sempre terei que estar na capital do Triângulo, rsss. Se você precisar de algo, também pode contar comigo sempre. É um pouco estranho essa amizade virtual, prefiro reunir nossa turma um dia e conhecer todos pessoalmente. Topa? Abraços.

A.

M.M.E. - domingo, 30 setembro 2012, 07:13

A., concordo com você, o mundo virtual nos aproxima, nos ajuda a estabelecermos novos contatos, mas vamos reunir um dia para podermos nos conhecer pessoalmente.

Abraços

M.

Quadro 3- Diálogo 3

A troca de mensagens estabelecidas no fórum como as apresentadas, nos permite inferir que a postagem inicial do cursista motiva os colegas a tecerem comentários, sendo estes, geradores de outros. Assim, uma rede vai sendo construída pelos participantes do fórum, que ao comentar a mensagem inicial se conecta ao outro, e ao receber um comentário de seu comentário, estabelece as afinidades, como as registradas no Quadro 1 entre M.M.E e C.N.M.

Atribuímos a esse contexto propício a empatia entre os participantes, assim como a significação linguística produzida pelas mensagens postadas, pois

[...] Na realidade, não são palavras o que pronunciamos ou escutamos, mas verdades ou mentiras, coisas boas ou más, importantes ou triviais, agradáveis ou desagradáveis, etc. A palavra está sempre carregada de um conteúdo ou de um sentido ideológico ou vivencial. É assim que compreendemos as palavras e somente reagimos àquelas que despertam em nós ressonâncias ideológicas ou concernentes à vida (Bakhtin, 2010, pp. 98-99). (grifo do autor).

A linguagem presente nas postagens cumpre a sua função social, a comunicação, e junto a ela, também se encontra para além de seu decodificar, o subtexto nela embutido, fazendo com que alguns dos participantes ultrapassassem os limites da conversação, chegando às vias do afetivo, do emocional.

Os postulados de Vigotski (2009) acerca do desenvolvimento humano e, consequentemente, da linguagem e da aprendizagem, são bastante esclarecedoras sobre a construção conjunta do conhecimento em qualquer ambiente, virtual ou presencial. Suas reflexões são certamente essenciais para uma visão de 
desenvolvimento que parta do social para o individual. Segundo o autor, essa relação não é direta e sim mediada, sendo a linguagem seu principal instrumento mediador. Para Vigostki (2009) o desenvolvimento da linguagem é primeiramente impulsionado pela necessidade de comunicação, sendo as principais funções desta $o$ intercâmbio social e o pensamento generalizante.

\section{O NÍVEL DE INTERATIVIDADE A PARTIR DO SNAPP}

Nesse fórum de apresentação, em especial, houve 20 participantes e 153 postagens. Do total de participantes, uma cursista não finalizou o curso de formação, porém participou dessa atividade. Dentre as postagens realizadas, 17 delas foram feitas pelo tutor formador e três cursistas realizaram apenas uma postagem.

De forma a visualizar as interações ocorridas no fórum de apresentação, utilizamos o Social Netwoks Adpting Pedagogical Practice (SNAPP) ${ }^{1}$, versão 1.5, que é um pluggin $^{2}$ desenvolvido como parte de um projeto voltado para o desenvolvimento de tecnologias de informação e comunicação (TICs) e recursos de visualização de dados mediados em redes sociais.

OSNAPP realiza a análise em tempo real de uma rede social epermite a visualização da atividade fórum de discussão dentro de sistemas de gestão de aprendizagem aberta. Ele serve essencialmente como um instrumento de diagnóstico, permitindo que o docente avalie os padrões de comportamento dos estudantes em relação ao aprendizado proposto pelo projeto de atividade, podendo intervir, se necessário, em tempo hábil.

A intencionalidade do uso desse plugin se deve ao fato de que ele permite, visualmente, olhar a rede constituída pelas postagens realizadas no fórum de apresentação do curso de formação CeaD/UFU, identificando os mais interativos e os menos interativos.

A materialização dessa rede está representada na Fig. 3, indicando as interações dos participantes realizadas no fórum de apresentação, sendo que os círculos na cor vermelha, representam os candidatos a tutores e o círculo de cor amarela, o tutor formador.

Mediante essa representação, temos clareza de que houve comunicação significativa nesse fórum, pois "[...] a comunicação pressupõe necessariamente generalização e desenvolvimento do significado da palavra, ou seja, a generalização se torna possível se há desenvolvimento de comunicação" (Vigotski, 2009, p. 12). 


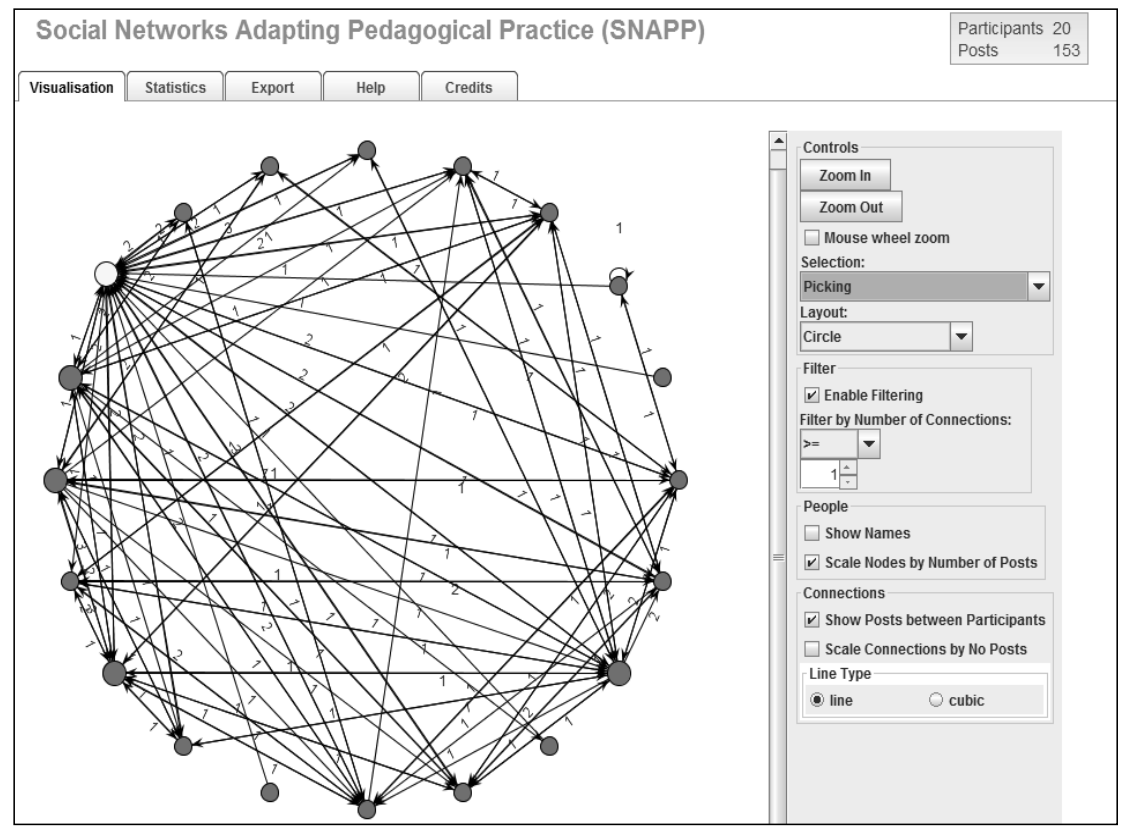

Figura 3. Interações no Fórum de Apresentação a partir do Snaap, com $n^{0}$ de postagem

A quantidade de interação é percebida pela diferença no tamanho dos círculos. O cursista menos interativo é representado pelo círculo de menor tamanho, e o mais interativo, pelo círculo maior.

O envio e o recebimento de postagens estão configuradas pelas setas indicativas de que o candidato recebeu $(\leftarrow)$ e/ou enviou $(\rightarrow)$ mensagens. Pela Fig. 3 é possível identificar a origem e o destinatário da mensagem, além de conter o número de vezes em que isso aconteceu.

O SNAAP permite, por meio de alguns recursos, a escolha do formato da imagem, a escala do número de postagens, a marcação delas entre os participantes, e também o nome dos integrantes do fórum. Nesse caso, não marcamos essa opção para preservar a identidade dos mesmos.

Ao observamos a rede formada pelas interações dos cursitas, identificamos, ainda, os participantes menos interativos, ou seja, aqueles que postaram apenas uma mensagem. Daí percebemos que o círculo da rede não se fecha porque alguns dos participantes pouco ou quase não interegiram com os outros colegas. O que significa dizer que esses não trocaram mensagens com todos da sala. 
Ao marcarmos a opção 'permitir filtragem', isolamos esses participantes menos interativos, e percebemos que um deles enviou mensagem para ele mesmo, conforme Fig. 4. Esse participante enviou duas mensagens (Fig. 3), uma para seu tutor formador e uma para si mesmo (Fig. 4).

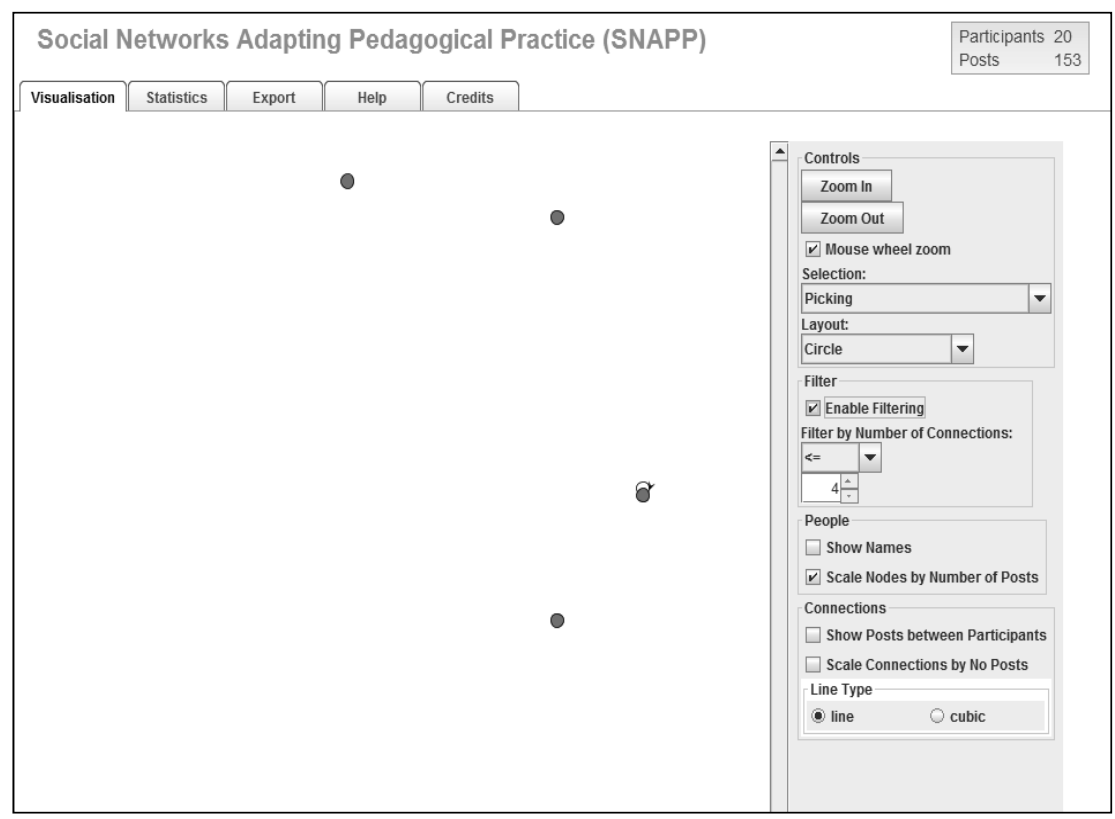

Figura 4. Participantes menos interativos no fórum de apresentação

A partir de um olhar mais atencioso, é possível perceber que alguns cursistas apenas inseriram uma postagem, não efetuando nenhuma interação com nenhum outro integrante do fórum. Ao contrário, outros, além de postarem a sua apresentação, receberam vários comentários dos colegas, fazendo com que respondessem esses comentários, estabelecendo assim, uma interação dentro do espaço. Isso se mostra pela quantidade de setas em direção do cursista. 


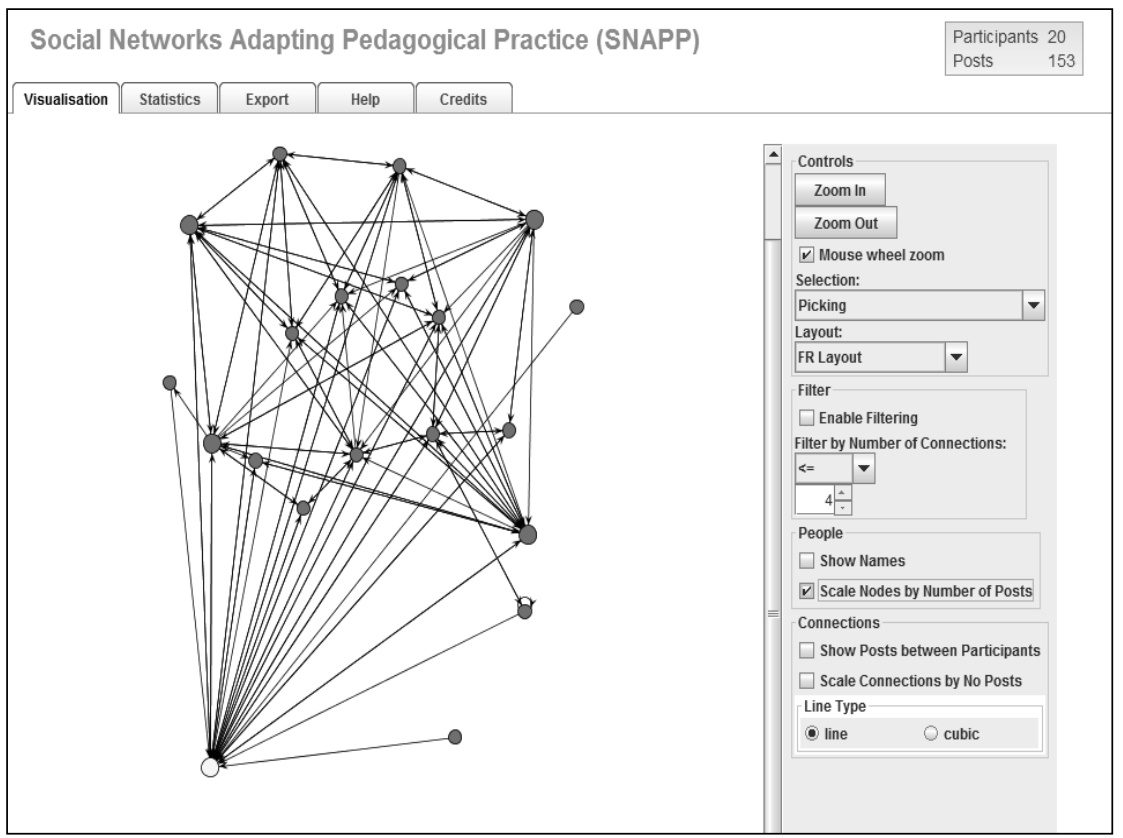

Figura 6. Participantes no fórum de apresentação - Layout SNAPP: FR Layout

O fórum é uma ferramenta de comunicação assíncrona que além de propiciar a discussão de temas entre os alunos e professores em um curso a distância, permite a troca de sentidos construídos pela singularidade. Apresenta-se assim, como um espaço privilegiado para a interação, local de intensas discussões e reflexões que podem levar os seus participantes à construção de um conhecimento conjunto e explícito que estará disponível para todos. Nesse caso, um fórum de discussão, direcionado a um conteúdo mais específico de um curso a distância.

A interação proporcionada por ele, o fórum, é uma de suas principais características. Assim, a interatividade possui três aspectos essenciais:

- Participação colaborativa: participar não é apenas responder "sim" ou "não", prestar contas ou escolher uma opção dada, significa intervenção na mensagem como cocriação da emissão e da recepção;

- Bidirecionalidade e dialógica: a comunicação é a produção conjunta da emissão e da recepção, os dois polos codificam e decodificam;

- Conexões em teias abertas: a comunicação supõe múltiplas redes articulatórias de conexões e liberdade de troca, associações e significações (Silva, 2006, p. 58). 
$\mathrm{Na} \mathrm{EAD}$, o fórum, por suas características e possibilidades, disponibiliza o diálogo, mas para que a mediação pedagógica seja ativa e haja a construção de um ambiente de aprendizagem crítica e significativa, os tutores devem atuar, conforme as seguintes características:

[...] dialogar permanentemente de acordo com o que acontece no momento; trocar experiências; debater dúvidas, questões ou problemas; apresentar perguntas orientadoras; auxiliar nas carências e dificuldades técnicas ou de conhecimento quando o aprendiz não consegue se conduzir sozinho; garantir a dinâmica do processo de aprendizagem; propor situações-problemas e desafios; desencadear e incentivar reflexões; criar intercâmbio entre a aprendizagem e a sociedade real onde nos encontramos, nos mais diferentes aspectos; colaborar para estabelecer conexões entre o conhecimento adquirido e novos conceitos, fazendo a ponte com outras situações análogas; colocar o aprendiz frente a frente com questões éticas, sociais, profissionais, conflituosas, por vezes; colaborar para desenvolver crítica com relação à quantidade e validade das informações obtidas; cooperar para que o aprendiz use e comande as novas tecnologias para aprendizagem e não seja comandado por elas ou por quem as tenha programado; colaborar para que se aprenda a comunicar conhecimentos, seja por intermédio de meios convencionais, seja mediante novas tecnologias (Masetto, 2003, p.49).

A interatividade está relacionada à troca de influências, ideias e permanente contribuição dos participantes. Se não houver interesse a princípio, ou seja, se o motivo que leva o cursista a realizar a tarefa, não coincide com objetivo da tarefa, é possível criar novos motivos, interesses e necessidades.

Para tanto, o resultado da atividade deve ser tão significativo, que se torne o motivo para o cursista participar novamente. A partir do momento que ele percebe os resultados do fórum, da participação de todos, mesmo que inicialmente ele não tenha sido motivado pela obrigação, começa a ser motivado pelos resultados.

O enunciado da atividade foi construído de forma clara e objetiva, seguindo os pressupostos da escrita na EaD. Acreditamos que esse seja um dos elementos contribuintes para o êxito do fórum de apresentação.

Diante da proposta da atividade, os objetivos foram alcançados tendo em vista que os cursistas estabeleceram vínculos afetivos com os colegas, conseguindo assim, estabelecer diálogos entre eles. Esses vínculos iniciais se reafirmaram em outras atividades coletivas, como a wiki.

O conteúdo das mensagens presentes no fórum de apresentação faz com que identifiquemos, no desenrolar dos diálogos, que os cursistas se interessaram em saber mais informações acerca dos colegas de sala, para assim se conhecerem melhor, 
e diante disso, descobrir as particularidades de cada um, estabelecendo, quem sabe, uma nova amizade, conforme o diálogo do Quadro 4.

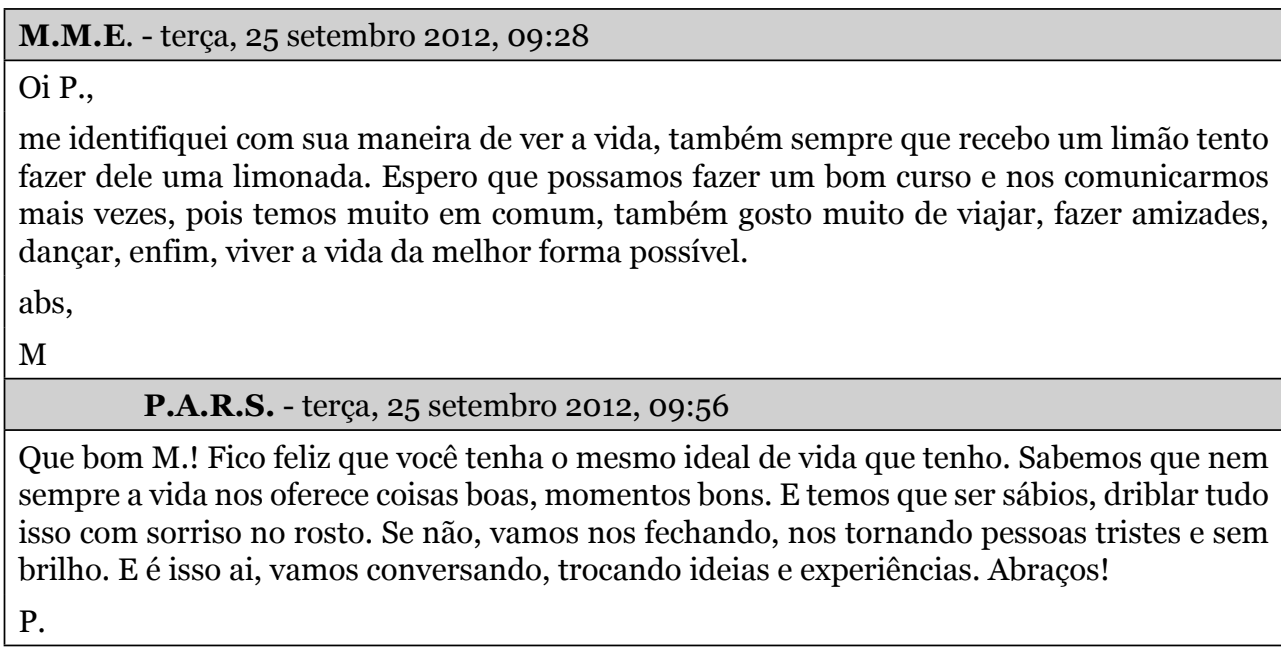

Quadro 4-Diálogo 4

\section{CONSIDERAÇÕES}

A intenção deste trabalho se pautou em mapear o perfil dos candidatos a tutores inscritos no processo seletivo simplificado para contratação de tutores para atuarem nos cursos a distância da UFU, que foram classificados na primeira etapa e convocados para a segunda, ou seja, aqueles designados a fazer o curso de formação oferecido pelo $\mathrm{CEaD}$.

Direcionados por essa intencionalidade, e motivados pela problemática instaurada pelo aumento da demanda por formação de atores para atuarem na EaD e primando pela qualidade da tutoria a ser realizada nos cursos a distância da UFU, tivemos como foco nesta investigação traçar o perfil dos candidatos com base nas informações registradas no AVA Moodle, especificamente, no fórum de apresentação do Módulo 1 do curso, assim como, em algumas das questões contidas no questionário de avaliação do curso.

Diante dos pontos abordados no desenrolar deste texto, apresentamos algumas considerações de forma a não se encerrar a discussão sobre o assunto, mas sim, provocar, a partir dos resultados obtidos, reflexões que possam vir a ser debatidas entre os interessados no assunto ou mesmo que subsidiem novas investigações. 
Nesse sentido, em meio ao que foi apresentado em relação à estrutura teóricodidático-pedagógica do curso de formação de tutores do $\mathrm{CEaD}$, consideramos que ele é uma formação inicial para os candidatos, com apresentação das ferramentas básicas do AVA Moodle, promovendo uma simulação rápida de atuação nos cursos a distância, não sendo possível atestar ao final, se houve apreensão da importância da tutoria nos cursos EaD nos diversos aspectos que ela abrange, seja domínio e apropriação dos recursos digitais do AVA, sejam os que se referem à mediação e linguagem dialógica.

Sobre o perfil dos candidatos a tutores consideramos que os inscritos no processo seletivo representam apenas uma pequena mostra, não sendo possível afirmar que ela seja representativa da totalidade de candidatos inscritos em todos os processos. Contudo, nos permite tomar conhecimento sobre eles diante dos aspectos relacionados à faixa etária, formação acadêmica, experiências e conhecimentos sobre a EaD, além de conhecermos sobre sua profissionalidade.

Mediante os dados relativos a conhecimento e experiência no campo da EaD e no AVA Moodle, destacamos que 38,9\% dos candidatos não conheciam o AVA Moodle antes de iniciar o curso de formação e, essa mesma porcentagem equivale para aqueles que indicaram ter conhecimento e alguma experiência na EaD, contudo, não como aluno, professor ou tutor, mas em outras áreas que a envolve.

Esse dado presente em um curso de formação inicial de tutores, com uma carga horária de 80 horas, nos coloca em alerta e ao mesmo tempo, permite predizer que os candidatos inseridos nesse percentual terão maiores dificuldades em lidar com as ferramentas do AVA Moodle, que aqueles 33,3\% que indicaram ter conhecimento do ambiente Moodle, sendo necessário, assim, um acompanhamento preventivo do tutor formador, nas questões de domínio e apropriação.

Por isso, as perguntas analisadas que estão contidas no questionário de avaliação do curso aplicado somente ao final do mesmo, se fossem respondidas e analisadas no início do curso, possibilitariam ao tutor formador e à própria equipe $\mathrm{CEaD}$, dar uma atenção mais direcionada a esses candidatos, a título de prevenir possíveis dissabores no futuro.

Os dados oriundos do mapeamento do perfil dos candidatos envolvidos neste estudo, nos levam a refletir sobre o desempenho da tutoria concomitantemente a outras atividades profissionais já assumidas, revelando a partir do que foi informado no AVA, que vários deles possuem mais de uma atividade laboral. 
Mediante a análise dos dados apresentados nesse subitem, não foi possível desviarmos a atenção em relação às condições colocadas pelo candidato. Isto nos faz pensar, dentre outras coisas, sobre em que condições o futuro tutor, caso venha a ser aprovado no processo, desenvolverá suas atribuições de tutoria em um curso a distância, se já exerce a docência em instituições públicas e/ou privadas, na educação básica e/ou no ensino superior e, a maioria deles com mais de um cargo na docência.

Em relação ao papel do fórum de apresentação no curso de formação acreditamos que ele seja uma atividade importante dentro do módulo inicial por permitir que o candidato exponha suas expectativas em relação ao curso e suas concepções em relação à EaD, oportunizando sua apresentação informal e motivando-o a interagir dentro do ambiente a partir das postagens dos outros integrantes da sala virtual.

Por meio da ferramenta fórum percebemos o quão importante são a desenvoltura do tutor ao lidar com ela e a atenção dada ao uso da linguagem correta no ambiente da EaD, pois "[...] a linguagem é, antes de tudo, um meio de comunicação social, de enunciação e compreensão" (Vigotski, 2009, p.11). O poder motivacional necessita estar presente em sua atuação no fórum, não deixando que as discussões nele presentes se esvaiam.

O limite deste trabalho não nos permite delongar sobre as atribuições do tutor, no entanto, nos prendemos aos objetivos propostos pela atividade e sua repercussão no fórum de apresentação. As mensagens iniciais de cada cursista postadas no fórum carregam significados singulares, mas ao mesmo tempo, foi a partir delas, mediante os enunciados nela contida, que os outros se sentiram convidados a respondê-las.

Com isso, gerou-se um alto número de mensagens no fórum de apresentação que foram mediadas pela linguagem, escrita e visual, ou seja, as palavras e a imagem, permeadas de sentidos e significados, capazes de originar afinidades entre os cursistas, promovendo uma harmonia entre eles no decorrer do curso.

O nível de interatividade no fórum foi analisado pelo SNAPP, permitindo assim, visualizar a rede que foi construída pelas mensagens enviadas e recebidas pelos participantes. O programa permitiu, ainda, a identificação de cursistas menos interativos e mais interativos. Acreditamos que a utilização desse programa no decorrer da atividade facilita a identificação de cursistas mais distantes da proposta, permitindo assim, uma recuperação no que diz respeito à interação dos participantes do fórum, promovendo uma integração total no ambiente. 
Assim sendo, ao fazermos emergir questionamentos a determinados pontos sobre o perfil dos candidatos a tutores, mediante o fórum de apresentação e as informações contidas no questionário de avaliação do curso de formação de tutores CEaD/UFU, poderemos, de certa forma, lidar melhor com as situações que se apresentam no contexto da EaD/UFU, pós-formação.

Por isso, acreditamos que este trabalho possa contribuir para os estudos que permeiam a EaD, mais especificamente no que diz respeito à formação de tutores, pois o mapeamento de perfis de candidatos se mostra necessário para corroborar o processo seletivo de tutores, permitindo, além de antever aqueles que mais se adequam aos cursos a distância da UFU, sanar as deficiências apresentadas, no decorrer do curso formativo, daqueles que estão mais distantes do perfil desejado pela instituição.

\section{NOTAS}

1. Para saber mais sobre o SNAPP, acesse o site: http://www.snappvis.org/?page_id=4

2. Na informática, um plugin ou módulo de extensão (também conhecido por plugin, add-in, add-on) é um programa de computador usado para adicionar funções a outros programas maiores, provendo alguma funcionalidade especial ou muito específica. Geralmente pequeno e leve, é usado somente sob demanda. Fonte: https:// pt.wikipedia.org/wiki/Plugin. Acesso em: 28 jun. 2013.

\section{REFERÊNCIAS BIBLIOGRÁFICAS}

Arruda, E. P.; Mourão, M. P. (Orgs.). (2012). Curso de Formação de Tutores para Educação a Distância. Versão 1.4 . Uberlândia: CEaD/UFU/UAB.

Arruda, E. P.; Mourão, M. P. (Orgs.). (2010). Curso de Formação de Tutores para Educação a Distância. Versão 1.2. Uberlândia: CEaD/UFU/UAB.

Bakhtin, M. M. (2010). Marxismo e filosofia da linguagem: problemas fundamentais do método sociológico da linguagem. 14. ed. São Paulo: Hucitec.

Brasil. (2005). Ministério da Educação. Decreto $n^{\circ}$ 5.622, de 19 de dezembro de 2005. Regulamenta o art. 80 da Lei no 9.394, de 20 de dezembro de 1996, que estabelece as diretrizes e bases da educação nacional. Brasília: MEC.
Brasil. (1996). Ministério da Educação. Lei $n^{o}$ 9.394, de 20 de dezembro de 1996. Estabelece as Diretrizes e Bases da Educação Nacional. Brasília: MEC.

Dotta, S.; Giordan, M. (2007). Tutoria em educação a distância: um processo dialógico. In: Encontro Internacional Virtual Educa Brasil, 7. São José dos Campos. Anais. São José dos Campos, (1-15).

Dotta, S.; Giordan, M. (2007). Formação de professores para interação em processos de tutoria pela Internet. In: Simpósio Internacional de Informática Educativa, 9. Porto, Portugal. Anais. Portugal, (1-6). Giordan, M.; Dotta, S. (2008). Estudo das interações mediadas por um serviço de tutoria pela Internet. Revista Linguagem 
\& Ensino, Pelotas, 11 (1), (127-143). [em línea] Disponível em: http://www.rle. ucpel.tche.br/index.php/rle/article/ (consulta 2013, 19 de junio).

Masetto, M. T. (2003). Competência pedagógica do professor universitário. São Paulo: Summus.

Mattar, J. (2012). Tutoria e interação em Educação a Distância. São Paulo: Cengage Learning.

Oliveira, S. C.; Filho, G. J. L. (2006). Animação de fóruns virtuais de discussão: novo caminho para a aprendizagem em EAD via web. In: Novas tecnologias na Educação, CINTED-UFRGS, 4 (2), [em línea] Disponível em: http:// www.cinted.ufrgs.br/renote/dez2006/ artigosrenote/25159.pdf (consulta 2013, 18 de junio).

Silva, M. (2006). Educação online. 2da. ed. São Paulo: Loyola.

Social Netwoks Adpting Pedagogical Practice (SNAPP). [em línea] Disponível em: http://www.snappvis.org (consulta 2013, 19 de junio).

Universidade Federal de Uberlândia. Faculdade de Educação. Centro de Educação a Distância ( $\mathrm{CEaD} / \mathrm{UAB} /$ UFU). (2012). Processo Seletivo simplificado para contratação de tutores a distância e presenciais temporários. Uberlândia. [em línea] Disponível em: http://www.cead.ufu.br/ sites/cead.ufu.br/files/Ed 0022012 CEAD FACED Tutores Esp Midias. pdf (consulta 2013, 5 de junio).

Universidade Federal de Uberlândia. Faculdade de Educação. Centro de Educação a Distância (CEaD/UAB/ UFU). (s/f). Centro de Educação a Distância. [em línea] Disponível em: http://www.cead.ufu.br (consulta 2013, 29 de junio)

Vigotski, L. S. (2009). A construção do pensamento e da linguagem. Tradução de Paulo Bezerra. 2da. ed. São Paulo: Martins Fontes.

\section{PERFIL ACADÉMICO Y PROFESIONAL DEL AUTOR}

Olíria Mendes Gimenes. Licenciada em Pedagogia pela Faculdade Católica de Uberlândia (2007), Mestre em Educação pela UFU (2012) e doutoranda em Educação pela Universidade de São Paulo (USP). Atua profissionalmente na rede municipal da cidade de Uberlândia/MG e como tutora formadora do CEaD/UFU desde 2009. Suas áreas de interesse são: formação de professores e tutores; educação a distância; letramento digital.

E-mail: oliriaudi@hotmail.com

\section{DIRECCIÓN DEL AUTOR}

Universidade de São Paulo (USP)

Programa de Pós-Graduação em Educação

Avenida de Universidade, 308 - Bloco B - Sala 18

São Paulo - SP

CEP 05508-040

Fecha de recepción del artículo: 15/11/13

Fecha de aceptación del artículo: 29/04/14 


\section{Como citar este artículo:}

Mendes Gimenes, O. (2014). O fórum de apresentação no curso de formação de tutores CEAD/UFU: um panorama do perfil dos candidatos e sua interatividade a partir do SNAPP. RIED. Revista Iberoamericana de Educación a Distancia, volumen $17, \mathrm{n}^{0} 2$, pp. 275-302. 